\title{
Tetramethylpyrazine-mediated regulation of CXCR4 in retinoblastoma is sensitive to cell density
}

\author{
NANDAN WU*, LIJUN XU*, YING YANG, NA YU, ZHANG ZHANG, PEI CHEN, \\ JING ZHANG, MINGJUN TANG, MENG YUAN, JIAN GE, KEMING YU and JING ZHUANG \\ State Key Laboratory of Ophthalmology, Zhongshan Ophthalmic Center, \\ Sun Yat-sen University, Guangzhou, Guangdong 510060, P.R. China
}

Received November 21, 2015; Accepted January 19, 2017

DOI: $10.3892 / \mathrm{mmr} .2017 .6293$

\begin{abstract}
Retinoblastoma is the most common ocular tumor in children, and it causes extensive damage. Current treatment options for retinoblastoma include surgery, chemotherapy, radiotherapy and cryotherapy. However, the majority of chemotherapy medicines cause complications and side effects that lead to severe impairment of patient health. Previous studies have reported that tetramethylpyrazine (TMP), which is an extract of the Chinese herbal medicine Chuanxiong, reduces the risk of multidrug resistance in chemotherapy and inhibits the proliferation and metastasis of various types of cancer cells. However, the underlying molecular mechanism of TMP in retinoblastoma remains unclear. The current study demonstrated that C-X-C chemokine receptor type 4 (CXCR4) was expressed in WERI-Rb1 cells and in retinoblastoma. Using reverse transcription-quantitative polymerase chain reaction and western blotting techniques, the current study demonstrated that TMP significantly downregulated the expression of CXCR4 in WERI-Rb1 cells cultured at high density, whereas it had a minor effect in low-density WERI-Rb1 cells; additionally, this effect occurred in a time-dependent manner. TMP inhibited the proliferation of WERI-Rb1 cells as effectively as a CXCR4 antagonist, AMD3100, consistent with a role of CXCR4 in cancer development. Notably, TMP did not affect the cell cycle of cells cultured at low density $\left(1 \times 10^{5}\right.$ cells $\left./ \mathrm{ml}\right)$, whereas it induced G1-phase arrest in high-density cells $\left(7.5 \times 10^{5}\right.$ cells $\left./ \mathrm{ml} ; \mathrm{P}<0.05\right)$. In addition, the expression of CXCR4 in primary rat retinal neurocytes was significantly downregulated by TMP treatment, and this treatment
\end{abstract}

Correspondence to: Professor Jing Zhuang, State Key Laboratory of Ophthalmology, Zhongshan Ophthalmic Center, Sun Yat-sen University, 54 South Xianlie Road, Guangzhou, Guangdong 510060, P.R. China

E-mail: zhuangj@mail.sysu.edu.cn

\section{*Contributed equally}

Key words: retinoblastoma, WERI-Rb1 cells, C-X-C chemokine receptor type 4 , tetramethylpyrazine, cell density protected primary rat retinal neurocytes from $\mathrm{H}_{2} \mathrm{O}_{2}$-induced damage. Thus, the results of this study indicate that TMP is a potential candidate for use in treatment of retinoblastoma, and also provides novel insights into the mechanisms of the anti-cancer and neuroprotective effects of this extract.

\section{Introduction}

Retinoblastoma, a malignant intraocular tumor that develops in the retina, is one of the most common ocular diseases affecting children, particularly young children $(<5$ years of age) (1). This tumor may be monocular or binocular successively or simultaneously, and it can cause serious damage to patient vision, even resulting in blindness. Furthermore, if this cancer is not treated early it can cause local or distant metastasis. This advanced form of retinoblastoma can be life threatening. Currently, various treatment strategies have been proposed, including surgery, radiotherapy, chemotherapy or a combination of these treatments (1). Chemotherapy is the major conservative treatment; however, almost all types of chemotherapy drugs are associated with severe systemic complications. Therefore, identification of novel therapeutic medicines to supplement chemotherapy in retinoblastoma is of urgently required. The ideal drug should inhibit the proliferation of retinoblastoma cells and also exert protective activity on neurons.

In recent years, accumulating evidence has suggested that tetramethylpyrazine (TMP), an extract of the Chinese herbal medicine Chuanxiong, administered in combination with other treatments may significantly reduce the risk of multidrug resistance during chemotherapy $(2,3)$ and inhibit the proliferation and metastasis of various types of cancer cells, including ovarian carcinoma, hepatocellular carcinoma, and lymphocytic leukemia cells (4-6). Vascular endothelial growth factor, hypoxia inducible factor- $1 \alpha$, the stromal cell-derived factor-1/C-X-C chemokine receptor type 4 (CXCR4) axis and $\mathrm{P}$-glycoprotein may be involved in TMP-mediated bioactivity (7-9). Currently, the function of TMP in retinoblastoma remains unknown.

Additionally, Chuanxiong has been used for the clinical treatment of neural diseases in Chinese medicine practices for $>2,000$ years. Pharmacological studies have demonstrated that TMP improves microcirculation through its anti-platelet 
aggregation effects and arteriolar regulation. It also possesses anti-oxidant, anti-free radical injury and calcium antagonist effects. Thus, TMP has been used as a supplement to prevent and treat cerebral ischemia and degenerative diseases of the central nervous system, including Alzheimer's disease, Parkinson's disease and multiple sclerosis. More importantly, it has been demonstrated to have only mild side effects during clinical treatment (10-13).

Furthermore, our previous study demonstrated that TMP protects primary rat brain neurocytes in vitro by markedly reducing the intracellular calcium level and inhibiting glutamate release via regulation of the expression of the chemokine receptor, CXCR4. It was also demonstrated that the TMP-mediated suppression of C6 glioma involves inhibition of CXCR4 expression (14). CXCR4 is a G-protein-coupled receptor with seven transmembrane-spanning domains most widely expressed in various types of cancer cells. It has been reported to mediate various processes that are essential for cancer progression, including tumor cell proliferation, metastasis, invasion and angiogenesis (15-17). Notably, it was observed that TMP does not affect the cell cycle when C6 glioma cells are at 50-80\% confluency. However, it can induce arrest in the $\mathrm{S}$ phase, significantly reducing the $\mathrm{G} 1$ and $\mathrm{G} 2$ populations of C6 glioma cells compared with controls, when cells are at $100 \%$ confluency (18).

Therefore, TMP may have a dual role in the inhibition of retinoblastoma growth and the protection of neurocytes. The present study was undertaken to examine whether TMP suppresses retinoblastoma cell growth by regulating CXCR4 expression and to determine whether its effect is associated with cell density.

\section{Materials and methods}

Patients. Retinoblastoma tissue was obtained from patients presenting at the Department of Pathology, Sun Yat-sen University (Guangzhou, China). The details and clinical demographics of patients are listed in Table I. This study was approved by the ethics committee of Sun Yat-sen University.

Reagents. The WERI-Rb1 human retinoblastoma cell line and HeLa cells were obtained from the American Type Culture Collection (Manassas, VA, USA). Sprague Dawley (SD) rats were obtained from the animal center of Zhongshan Ophthalmic Center, Sun Yat-sen University. TMP, AMD3100, DMSO and propidium iodide (PI) were purchased from Sigma-Aldrich (Merck KGaA, Darmstadt, Germany). Rabbit anti-CXCR4 and GAPDH, mouse anti-microtubule associated protein-2 (MAP-2) primary polyclonal antibodies were purchased from Abcam (Cambridge, UK; cat. no. ab2047), ProteinTech Group, Inc. (Chicago, IL, USA; cat. no. 10494-1-AP), and Boster Biological Technology, Ltd. (Wuhan, China; cat. no. BM1243), respectively. Horseradish peroxidase (HRP)-conjugated anti-rabbit IgG, Alexa Fluor 555 anti-rabbit IgG and Alexa Fluor 488 anti-mouse IgG were purchased from Cell Signaling Technology, Inc. (Danvers, MA, USA; cat. nos. 7074, 4413 and 4408, respectively). TRIzol Reagent and all of the cell culture media/reagents and salt solutions were obtained from Invitrogen (Thermo Fisher Scientific, Inc., Waltham, MA, USA). A SYBR PrimeScript ${ }^{\mathrm{TM}}$ RT-PCR kit was purchased from Takara
Biotechnology Co., Ltd. (Dalian, China). Amersham ECL reagents for western blotting were obtained from GE Healthcare Bio-Sciences (Pittsburgh, PA, USA).

Cell culture. WERI-Rb1 and HeLa cells were cultured in RPMI-1640 medium and Dulbecco's modified Eagle's medium (DMEM), respectively, supplemented with $10 \%$ fetal bovine serum, $100 \mathrm{U} / \mathrm{ml}$ penicillin and $100 \mathrm{mg} / \mathrm{ml}$ streptomycin in a humidified atmosphere of $5 \%$ carbon dioxide at $37^{\circ} \mathrm{C}$. For primary retinal neurocyte culture, the protocol was as follows: Briefly, P1-day-old SD rats $(n=9)$ were sacrificed by an intraperitoneal injection of Nembutal $(60 \mathrm{mg} / \mathrm{kg}$; Sigma-Aldrich). The retinas that were separated from the enucleated eyeballs were incubated for $20 \mathrm{~min}$ at $37^{\circ} \mathrm{C}$ in a solution containing $0.125 \%$ trypsin, to dissociate cells. To yield a suspension of single cells, the tissue was then triturated sequentially through a narrow-bore Pasteur pipette in a solution of DMEM supplemented with $10 \%$ fetal bovine serum. Cells were plated at a density of $\sim 1 \times 10^{6}$ cells $/ \mathrm{ml}$ on a culture plate pre-coated with $0.01 \%$ poly-L-lysine and cultured in DMEM supplemented with $10 \%$ fetal bovine serum, in a humidified atmosphere of $5 \%$ carbon dioxide at $37^{\circ} \mathrm{C}$ for $2 \mathrm{~h}$. After $12 \mathrm{~h}$, the cells were treated with $10 \mu \mathrm{M}$ Ara-C (Sigma-Aldrich) to suppress the growth of non-neurocytes. TMP was dissolved in component solvent (DMSO: saline, 1:1) and AMD3100 was dissolved in saline to the appropriate concentrations. The component solvent and saline were applied as vehicle controls.

Cell viability assays using cell counting Kit-8 (CCK-8). Cell viability was measured using a CCK-8 (Dojindo Molecular Technologies, Inc., Kumamoto, Japan). Exponentially growing WERI-Rb1 cells $\left(1 \times 10^{5}\right.$ or $7.5 \times 10^{5}$ cells $\left./ \mathrm{ml}\right)$ were seeded in a 96-well plate in $100 \mu \mathrm{l}$ complete medium for $4 \mathrm{~h}$ at $37^{\circ} \mathrm{C}$ prior to addition of $200 \mu \mathrm{M}$ TMP, $10 \mu \mathrm{g} / \mathrm{ml}$ AMD3100 or a vehicle control. After $24 \mathrm{~h}$ of treatment, $10 \mu \mathrm{l} \mathrm{CCK}-8$ reagent was added to each well and incubated at $37^{\circ} \mathrm{C}$ for $1 \mathrm{~h}$. Subsequently, absorbance was measured at $450 \mathrm{~nm}$ using a fluorescence plate reader (Power Wave XS; BioTek China, Beijing, China). Cell viability was determined by the optical density ratio of treated cells over the untreated control.

Cell cycle assay. WERI-Rb1 cells were plated at a high cell density $\left(7.5 \times 10^{5}\right.$ cells $\left./ \mathrm{ml}\right)$ or low cell density $\left(1 \times 10^{5}\right.$ cells $\left./ \mathrm{ml}\right)$ and treated with TMP $(200 \mu \mathrm{M})$ or a vehicle control. Cells were collected after $24 \mathrm{~h}$ of treatment and washed with ice-cold PBS and then fixed with $75 \%$ ice-cold ethanol at $4^{\circ} \mathrm{C}$ overnight. Before analysis, the cells were washed twice with PBS and incubated in a PI staining solution $(0.05 \mathrm{mg} / \mathrm{ml} \mathrm{PI}$, $1 \mathrm{mM}$ EDTA, $0.1 \%$ Triton-X-100 ${ }^{\mathrm{TM}}$ and $1 \mathrm{mg} / \mathrm{ml}$ RNase A) for $30 \mathrm{~min}$ at $37^{\circ} \mathrm{C}$. Subsequently, fluorescent cells were analyzed using a BD FACSort ${ }^{\mathrm{TM}}$ flow cytometer (BD Biosciences, San Jose, CA, USA). The data were analyzed with Flow Jo software (Tree Star, Inc., Ashland, OR, USA).

Reverse transcription-polymerase chain reaction (RT-PCR) assay. Total RNA was isolated with TRIzol Reagent and dissolved in RNase-free water. Total RNA ( $1 \mu \mathrm{g})$ was subjected to reverse transcription using a PrimeScript ${ }^{\mathrm{TM}}$ RT Reagent kit (Takara Biotechnology Co., Ltd., Dalian, China) following the manufacturer's protocol. 
Table I. Clinical demographics of 12 retinoblastoma patients.

\begin{tabular}{lccc}
\hline $\begin{array}{l}\text { Patient } \\
\text { number }\end{array}$ & $\begin{array}{c}\text { Age at } \\
\text { diagnosis (months) }\end{array}$ & Sex (M/F) & UL/BL \\
\hline 1 & 48 & F & UL \\
2 & 24 & F & UL \\
3 & 12 & F & UL \\
4 & 36 & F & UL \\
5 & 48 & M & UL \\
6 & 25 & M & BL \\
7 & 20 & M & UL \\
8 & 28 & M & UL \\
9 & 11 & F & UL \\
10 & 36 & M & UL \\
11 & 14 & F & UL \\
12 & 26 & M & BL \\
\hline
\end{tabular}

M, male; F, female; UL, unilateral; BL, bilateral.

Semi-quantitative PCR was performed to measure the expression of CXCR4 in WERI-Rb1 cells and HeLa cells under normal growth conditions using an automated thermocycler (Biometra GmbH, Göttingen, Germany). The PCR program was as follows: Pre-denaturation at $94^{\circ} \mathrm{C}$ for $5 \mathrm{~min}$; and 30 cycles of denaturation at $94^{\circ} \mathrm{C}$ for $1 \mathrm{~min}$, annealing at $60^{\circ} \mathrm{C}$, and extension at $72^{\circ} \mathrm{C}$ for $1 \mathrm{~min}$. PCR products were separated by $2 \%$ agarose gel electrophoresis, and the band intensities on the resulting gels were determined by Scion Image software (Scion Image Corporation, Fredrick, MD, USA). $\beta$-actin gene expression was examined as an internal control. Quantitative PCR was employed to compare the expression of CXCR4 in WERI-Rb1 cells treated with TMP $(200 \mu \mathrm{M})$ or a vehicle control using the SYBR Green system (Takara Biotechnology Co., Ltd.), using the aforementioned thermocycling conditions. The quantity of target gene mRNA relative to that of the internal control gene, $\beta$-actin, was calculated using the $2^{-\Delta \Delta C T}$ method (19). The following primer pairs were used: $C X C R 4$, 5'-CTTATCCTGCCTGGTATTGTC-3' and 5'-CAATGTAGT AAGGCAGCCAAC-3'; and for $\beta$-actin, 5'-CACCACACC TTCTACAATGAG-3' and 5'-TAGCACAGCCTGGATAGC AAC-3'. The data were analyzed in triplicate.

Western blot assay. WERI-Rb1 cells were seeded in $60 \mathrm{~mm}$ dishes at different cell densities $\left(1 \times 10^{5}\right.$ or $7.5 \times 10^{5}$ cells $\left./ \mathrm{ml}\right)$ and treated with TMP $(200 \mu \mathrm{M})$ or a vehicle control for varying durations (12 or $24 \mathrm{~h}$ ). After treatment, the cells were washed with PBS and collected in radioimmunoprecipitation assay lysis buffer (Beyotime Institute of Biotechnology, Jiangsu, China). According to the bicinchoninic acid method for protein quantification, equal amounts of protein (30 $\mu \mathrm{g} /$ well) were separated on an $8 \%$ SDS-polyacrylamide gel by electrophoresis and electrophoretically transferred to a PVDF membrane (EMD Millipore, Billerica, MA, USA) at $250 \mathrm{~mA}$ for $1.5 \mathrm{~h}$. The membrane was blocked with a solution of $5 \%$ dried fat-free milk in TBS-Tween (TBS containing $0.1 \%$ Tween-20) for $2 \mathrm{~h}$, and then membrane-bound proteins were probed with primary antibodies against CXCR4 (1:500 dilution) and GAPDH (1:1,000 dilution) at $4^{\circ} \mathrm{C}$ overnight. Subsequently, the membrane was washed 3 times with TBST for 5 min each time, followed by incubation with HRP-conjugated anti-rabbit $\operatorname{IgG}(1: 10,000)$ for $1 \mathrm{~h}$ at room temperature. GAPDH served as an internal control. Finally, protein bands were detected with enhanced chemiluminescence (EMD Millipore). Densitometric analysis of the bands compared with the density of CXCR4 and GAPDH was performed using ImageJ software (imagej.nih.gov).

Immunohistofluorescence assay. Human retinoblastoma tissues were originally fixed with $10 \%$ formalin and then embedded in optimal cutting temperature compound. Retinoblastoma tissue sections of $6 \mu \mathrm{m}$ were used. Human retinoblastoma tissue, untreated WERI-Rb1 cells and primary cultured neurocytes were fixed with ice-cold $100 \%$ methanol for $15 \mathrm{~min}$ and then blocked with $10 \%$ normal goat serum (Cell Signaling Technology, Inc., Danvers, MA, USA) for $30 \mathrm{~min}$. Subsequently, the human retinoblastoma tissue and untreated WERI-Rb1 cells were incubated overnight at $4^{\circ} \mathrm{C}$ with primary antibody against CXCR4 (1:500 dilution), and primary cultured neurocytes were incubated with primary antibodies against CXCR4 (1:500 dilution) and MAP-2 (1:100 dilution). Alexa Fluor 555 anti-rabbit $\lg$ and Alexa Fluor 488 anti-mouse $\lg \mathrm{G}$ were used as secondary antibodies (1:500 dilution) for a further $1 \mathrm{~h}$ at room temperature, and nuclei were stained with DAPI.

$\mathrm{H}_{2} \mathrm{O}_{2}$-induced damage and MTT viability assays. Primary cultured rat retinal neurons were seeded in a 24-well plate in $500 \mu \mathrm{l}$ complete medium and then treated with TMP $(200 \mu \mathrm{M})$ or a vehicle control for $48 \mathrm{~h}$ at $37^{\circ} \mathrm{C}$. After the TMP treatment, the cells were treated with $\mathrm{H}_{2} \mathrm{O}_{2}(600 \mu \mathrm{M})$ for $15 \mathrm{~min}$ at $37^{\circ} \mathrm{C}$. Subsequently, they were incubated in $\mathrm{H}_{2} \mathrm{O}_{2}$-free medium with TMP or a vehicle control at $37^{\circ} \mathrm{C}$ for $2.5 \mathrm{~h}$. After 0,24 or $48 \mathrm{~h}, 50 \mu \mathrm{l}$ MTT was add to each well, the plate was incubated for $4 \mathrm{~h}$ at $37^{\circ} \mathrm{C}$ and $500 \mu \mathrm{l}$ DMSO was added to each well. Absorbance was measured at $490 \mathrm{~nm}$ using a fluorescence plate reader (Power Wave XS). Cell viability was determined according to the optical density ratio of a treated culture over an untreated control.

Statistical analysis. All experiments were performed at least three times in vitro. Data are expressed as the mean \pm standard error. Differences between mean values were evaluated with two-tailed Student's $t$-test (for 2 groups). All calculations and statistical tests were performed using Excel 2003 (Microsoft Corporation, Redmond, WA, USA). $\mathrm{P}<0.05$ was considered to indicate a statistically significant difference.

\section{Results}

CXCR4 is expressed in WERI-RbI cells and retinoblastoma tissue. As CXCR4 has important roles in cancer development and progression (15), CXCR4 expression in WERI-Rb1 cells and in HeLa cells was determined as a positive control. Total RNA and whole-cell lysates were obtained for semi-quantitative PCR and western blot analyses. As demonstrated in Fig. 1A and B, CXCR4 mRNA and protein expression 


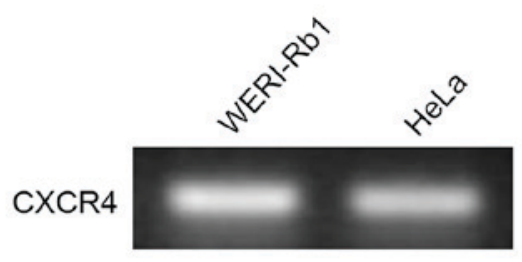

$\beta$-actin

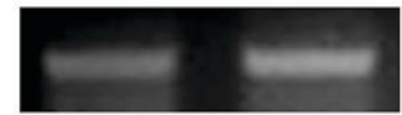

B

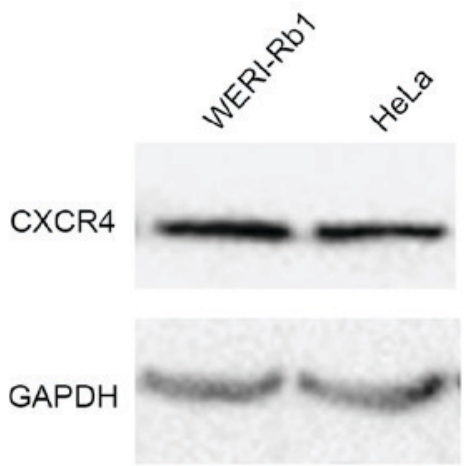

C
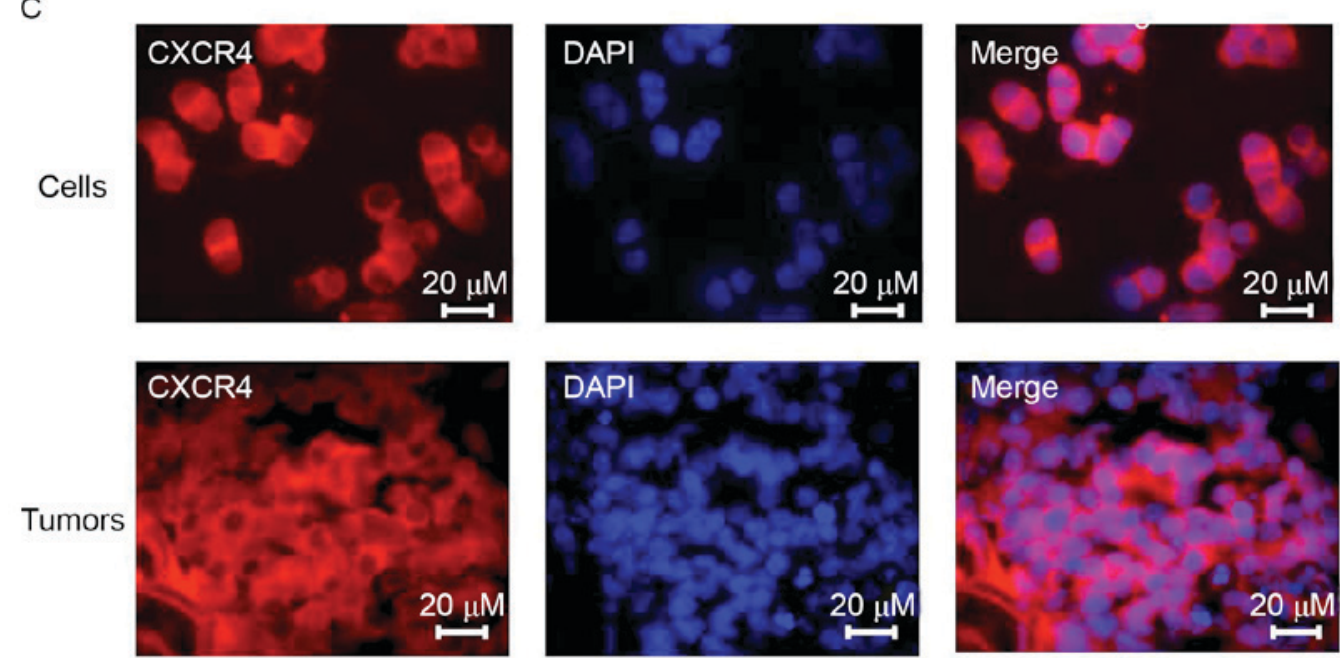

Figure 1. CXCR4 is highly expressed in WERI-Rb1 cells and tumors. CXCR4 is highly expressed in WERI-Rb1 cells compared with positive control HeLa cells, as demonstrated by (A) reverse transcription-polymerase chain reaction and (B) western blotting analysis. (C) Immunohistofluorescence results demonstrated that CXCR4 is expressed in WERI-Rb1 cells and retinoblastoma tumors (Original magnification x100). CXCR4, C-X-C chemokine receptor type 4.

was higher in WERI-Rb1 cells compared with HeLa cells. Immunofluorescence staining confirmed the expression of CXCR4 in the cytoplasm of WERI-Rb1 cells and retinoblastoma tissue (Fig. 1C). Therefore, it may be a potential therapeutic target for retinoblastoma treatment.

TMP-mediated downregulation of CXCR4 in WERI-RbI cells is dependent on cell density. It was previously reported that TMP suppresses the growth of C6 glioma by reducing the expression of CXCR4 (14). To examine whether TMP downregulates $C X C R 4$ expression in WERI-Rb1 cells and to determine whether its effect is associated with cell density, we measured the mRNA and protein levels of CXCR4 after TMP treatment $(12$ or $24 \mathrm{~h})$ in WERI-Rb1 cells plated at a low density $\left(1 \times 10^{5}\right.$ cells $\left./ \mathrm{ml}\right)$ or high density $\left(7.5 \times 10^{5}\right.$ cells $\left./ \mathrm{ml}\right)$. Fig. 2A demonstrated that the mRNA expression of CXCR4 in WERI-Rb1 cells was not altered after TMP treatment for $12 \mathrm{~h}$ at the low density; no significant difference was observed between the test and control groups. At $24 \mathrm{~h}, C X C R 4$ expression was marginally downregulated by the TMP treatment, exhibiting a $12.8 \%$ decrease $(\mathrm{P}<0.05)$. However, $C X C R 4$ mRNA expression was significantly decreased after TMP treatment for 12 and $24 \mathrm{~h}$ at the high cell density, exhibiting a 28.9 and $37.5 \%$ decrease, respectively $(\mathrm{P}<0.05$; Fig. $2 \mathrm{~A})$. Moreover, the decrease in CXCR4 mRNA expression at the high cell density was 2.93-fold greater than that at the low cell density at the
24 h time point $(\mathrm{P}<0.05$; Fig. 2). The results of western blotting were consistent with those of RT-qPCR (Fig. 2B). Relative quantification of CXCR4 expression revealed that there was also no significant difference between the test and control groups after TMP treatment at the $12 \mathrm{~h}$ time point at the low density, with a $14.3 \%$ decrease in $C X C R 4$ expression at the $24 \mathrm{~h}$ time point $(\mathrm{P}<0.05$; Fig. $2 \mathrm{C})$. Similarly, its expression was markedly decreased after TMP treatment for 12 and $24 \mathrm{~h}$ at the high cell density, exhibiting a 22.9 and $38.7 \%$ decrease, respectively ( $\mathrm{P}<0.05$; Fig. $2 \mathrm{C}$ ), and the decrease in its expression at the high cell density was 2.76 -fold greater than that at the low cell density at $24 \mathrm{~h}$ time point $(\mathrm{P}<0.05$; Fig. $2 \mathrm{C})$. These findings further confirm that TMP significantly inhibits CXCR4 expression in WERI-Rb1 cells and that its effect is sensitive to cell density. Furthermore, TMP treatment downregulated CXCR4 expression in WERI-Rb1 cells in a time-dependent manner (Fig. 2). These results further support the hypothesis that CXCR4 may be involved in mediating the effect of TMP on retinoblastoma and that TMP-mediated downregulation of CXCR4 may be associated with cell density.

Effects of TMP on inhibiting proliferation and the cell cycle of WERI-Rbl cells are dependent on cell density. Considering that the TMP-mediated downregulation of CXCR4 in WERI-Rb1 cells depends on cell density and that CXCR4 expression is closely associated with to the 

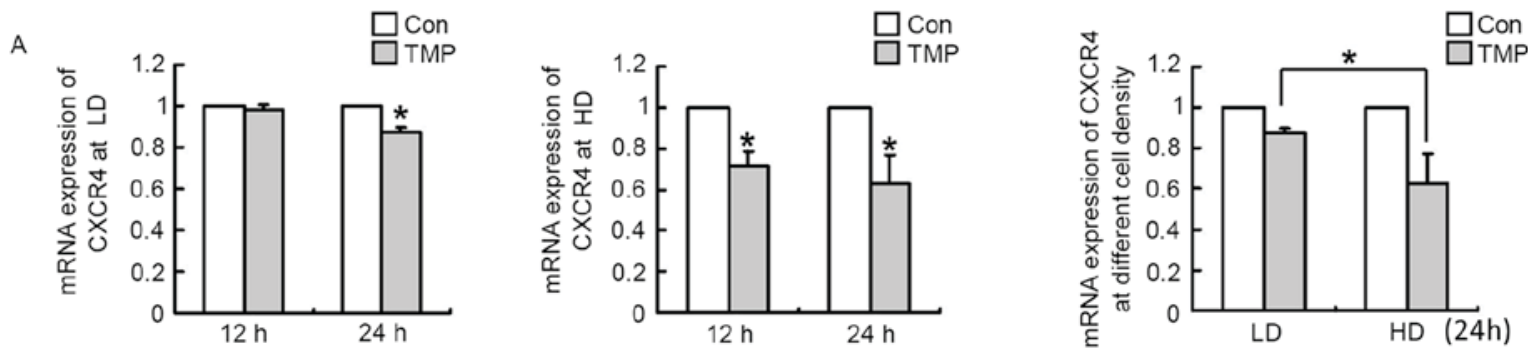

B
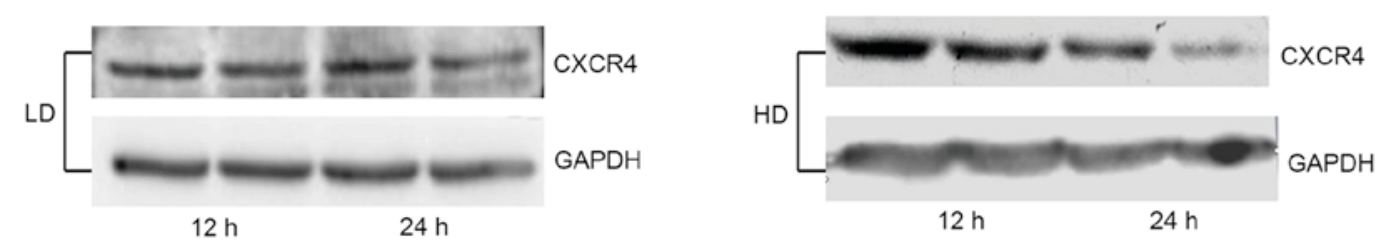

C
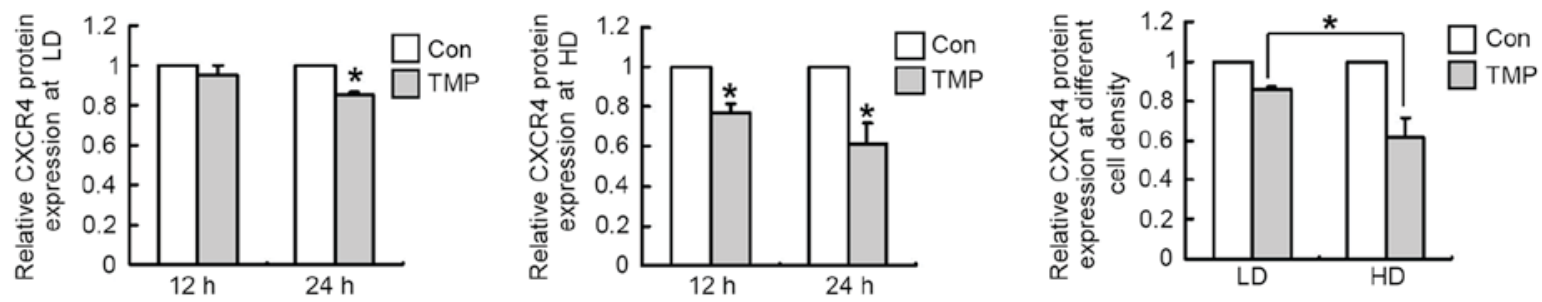

Figure 2. Downregulation of CXCR4 by TMP is sensitive to cell density. (A) Reverse transcription-quantitative polymerase chain reaction indicates that the mRNA expression of CXCR4 in WERI-Rb1 cells is downregulated by TMP at HD more effectively than at LD and that this effect occurs in a time-dependent manner. (B) Western blotting also indicates that the TMP-mediated suppression of CXCR4 expression in WERI-Rb1 cells is dependent on cell density. (C) Relative quantification of CXCR4 expression was performed by densitometry. All results were confirmed by three independent experiments ( $\mathrm{P}<0.05$ vs. Con, or comparison indicated by brackets). CXCR4, C-X-C chemokine receptor type 4; Con, control; TMP, tetramethylpyrazine; LD, low cell density; HD, high cell density.

proliferation of cancer cells, WERI-Rb1 cells were seeded at different cell densities $\left(10^{5}\right.$ or $7.5 \times 10^{5}$ cells $\left./ \mathrm{ml}\right)$ to determine the bioactivity of TMP on WERI-Rb1 cell growth and whether the inhibitory effect is associated with cell density. AMD 3100, a CXCR4 antagonist, was used as a positive control. As presented in Fig. 3A, TMP $(200 \mu \mathrm{M})$ reduced WERI-Rb1 cell viability at after $24 \mathrm{~h}$ of treatment, and this inhibition was stronger at the high cell density than at the low cell density, with inhibition rates of 10 and $27 \%$, respectively $(\mathrm{P}<0.05)$. AMD3100-treated WERI-Rb1 cells also exhibited reduced viability in a density-dependent manner, with inhibition rates of 8 and $24 \%$ at the low cell density and at the high cell density, respectively ( $\mathrm{P}<0.05$; Fig. $3 \mathrm{~B})$. The inhibition of cell growth may be a result of cell cycle arrest. To determine whether the inhibitory effects of TMP on WERI-Rb1 cell proliferation at different cell densities involves cell cycle alterations, the cell cycle profiles of WERI-Rb1 cells at different cell densities were examined by flow cytometry. The cell cycle was analyzed after treatment with TMP for $24 \mathrm{~h}$, and the results demonstrated that at a low cell density $\left(1 \times 10^{5}\right.$ cells $\left./ \mathrm{ml}\right)$, there were no significant differences in the cell cycle profiles of WERI-Rb1 cells between the test and control groups (Fig. 3C). However, TMP treatment was capable of inducing G1 phase arrest $(62.83 \pm 7.53 \%)$ in the high-density cells $\left(7.5 \times 10^{5}\right.$ cells $\left./ \mathrm{ml}\right)$ compared with control cells $(55.52 \pm 6.86 \%$; $\mathrm{P}<0.05$; Fig. 3D). Therefore, the results demonstrated that the inhibition of WERI-Rb1 cell proliferation by TMP was greater at the high cell density than at the low density. Furthermore, its inhibitory effect on cell proliferation was induced by other factors besides the arrest of the cell cycle at the G1 phase and cell cycle inhibition.

TMP downregulates the expression of CXCR4 in primary rat retinalneurocytes and protects these cells from $\mathrm{H}_{2} \mathrm{O}_{2}$-induced damage. Retinoblastoma is a malignant intraocular tumor that arises in the retina, and development of this type of tumor can cause injury to retinal neurons. Our previous studies have verified that TMP protects rat cerebral neurons by downregulating CXCR4 expression (14). To confirm that this extract has protective effects on retinal neurons, the expression of CXCR4 in primary rat retinal neurocytes was measured in vitro. Dual immunofluorescence staining for MAP-2 and CXCR4 revealed that CXCR4 was expressed in retinal neurons. MAP-2 was used as a marker of neuronal cells (Fig. 4A). After TMP treatment for 24 h, RT-qPCR was performed to determine CXCR4 mRNA expression in primary retinal neurocytes. As demonstrated in Fig. 4B, TMP significantly inhibited CXCR4 mRNA expression in these cells compared with the control cells $(\mathrm{P}<0.05)$, with an inhibition rate of $42.9 \%$. Subsequently, retinal neurocytes were pretreated with TMP or a vehicle control for $48 \mathrm{~h}$ and then the cells were exposed to $\mathrm{H}_{2} \mathrm{O}_{2}(600 \mu \mathrm{M})$ for $15 \mathrm{~min}$. Subsequently, the cells were incubated in an $\mathrm{H}_{2} \mathrm{O}_{2}$-free medium with TMP or a vehicle control at $37^{\circ} \mathrm{C}$. After 0 , 
A

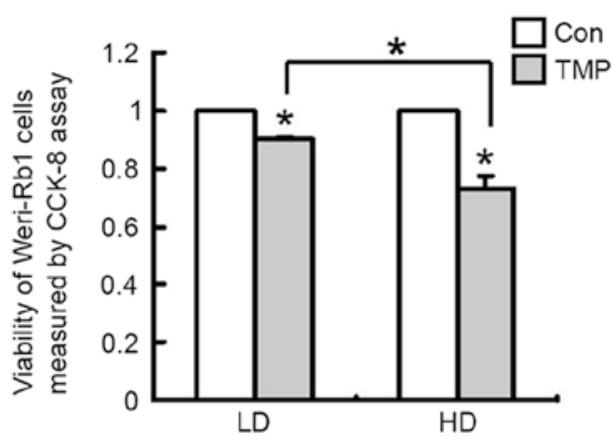

$\mathrm{C}$
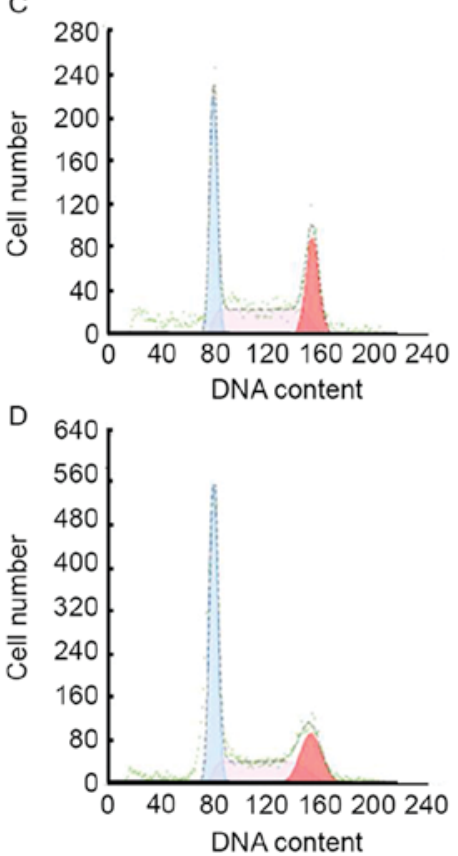
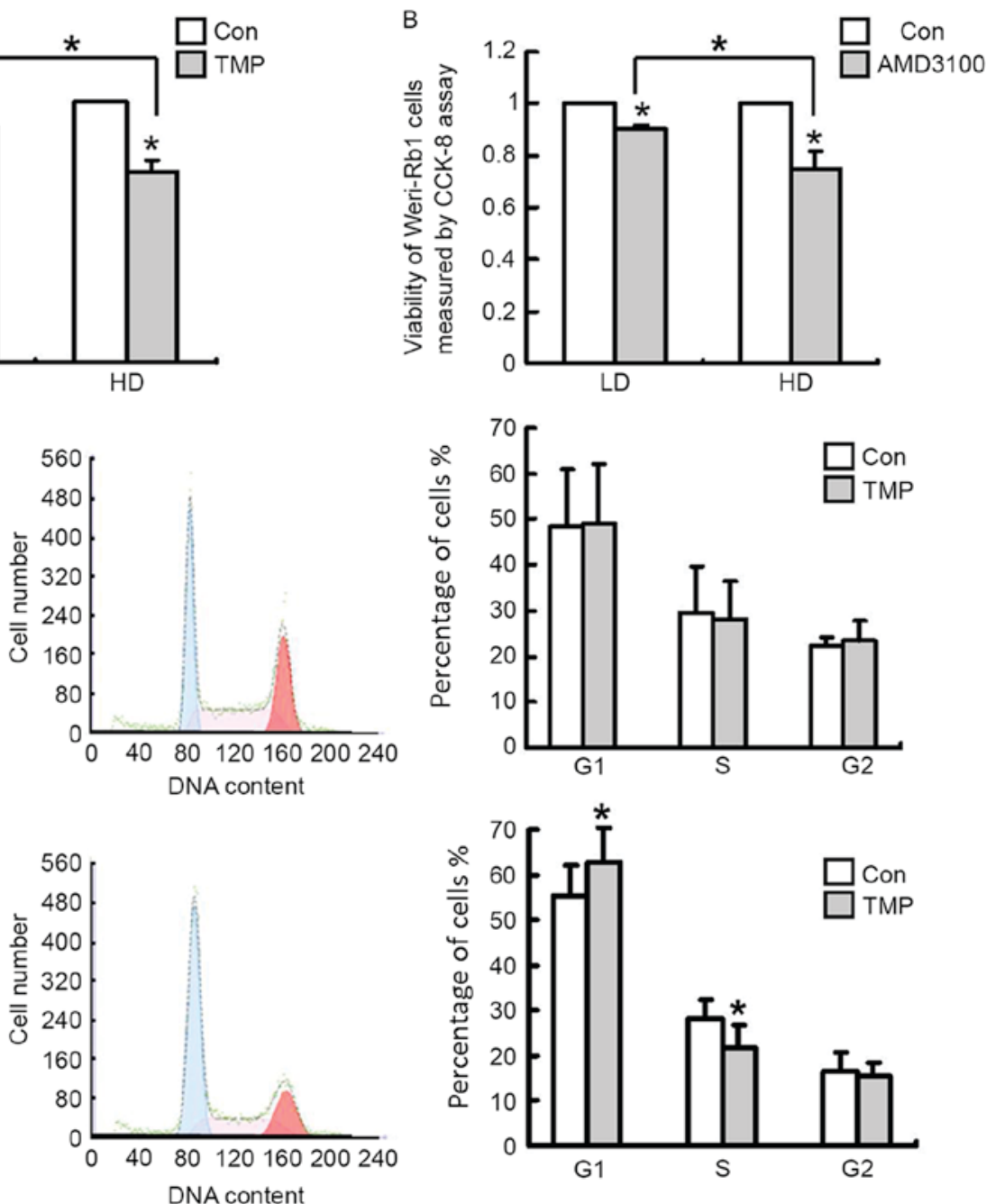

Figure 3. TMP $(200 \mu \mathrm{M})$ reduces cell viability and affects the cell cycle of WERI-Rb1 cells. (A) Viability of HD WERI-Rb1 cells (7.5x10 ${ }^{5}$ cells/ml) is reduced by TMP treatment. By contrast, the inhibitory effect of TMP is less potent at LD (1x10 cells/ml). (B) The inhibitory effect of AMD3100 (10 ng/ml), a CXCR4 antagonist, on WERI-Rb1 cells is also sensitive to cell density. Cell viability was analyzed by the CCK- 8 assay, and the data are presented as the survival rate relative to Con group. (C) TMP (200 $\mu \mathrm{M}$ for $24 \mathrm{~h})$ does not alter the cell cycle profile of LD WERI-Rb1 cells. (D) WERI-Rb1 cells arrested at the G1phase fail to enter into the $\mathrm{S}$ and $\mathrm{G} 2 / \mathrm{M}$ phases compared with controls when they are cultured at HD. All results were confirmed in three independent experiments ( ${ }^{*} \mathrm{P}<0.05$ vs. Con, or comparison indicated by brackets). CCK-8, Cell Counting Kit-8; Con, control; TMP, tetramethylpyrazine; LD, low cell density; HD, high cell density.

24 or $48 \mathrm{~h}$, an MTT assay was performed to measure cell viability. As demonstrated in Fig. 4C, neurons in the experimental group exhibited increased cell viability compared with the control group, with a viable cell rate increase to $120 \%(24 \mathrm{~h})$ or $126 \%(48 \mathrm{~h})$ relative to the control $(\mathrm{P}<0.05)$; at $0 \mathrm{~h}$ no significant difference was observed between the two groups. Additionally, the effect occurred in a time-dependent manner. Therefore, the results indicated that TMP possesses an anti-retinoblastoma function and exerts a protective effect on neurons.

\section{Discussion}

A growing body of evidence suggests that TMP possesses a potent inhibitory effect on cancer, and the relevant molecular mechanisms involved have been reported to include decreased DNA synthesis in cells via inhibition of mitosis and reduced of the expression of resistant genes (2). The present study demonstrated that TMP downregulated the expression of CXCR4 at the RNA and protein levels in WERI-Rb1 cells, and that it reduced WERI-Rb1 cell viability. Notably, the effect of TMP on WERI-Rb1 cells was sensitive to cell density. At a high cell density, the expression of CXCR4 was reduced dramatically, and cell viability was strongly inhibited by TMP treatment. However, the effect of TMP was minimal at a low cell density. In addition, TMP downregulated the expression of CXCR4 in rat retinal neurocytes and protected them from $\mathrm{H}_{2} \mathrm{O}_{2}$-induced damage in vitro.

Previous studies have indicated that CXCR4 has important roles in tumor progression (15-17). For example, treatment with AMD3100 (a CXCR4 antagonist) or chemotherapy combined with AMD3100 has been shown to induce caspase-3-mediated apoptosis and to inhibit glioma growth in vivo (20). A high level of CXCR4 expression promotes tumor proliferation, angiogenesis, migration and metastasis (21). It has been demonstrated that the expression of CXCR4 in WERI-Rb1 cells was also dependent on cell density, as expression in high-density cells was higher than that in low-density cells (unpublished data). 
A $\quad$ MAP-2

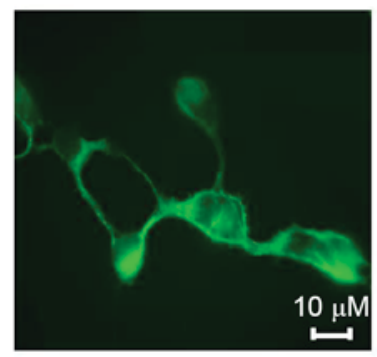

CXCR4

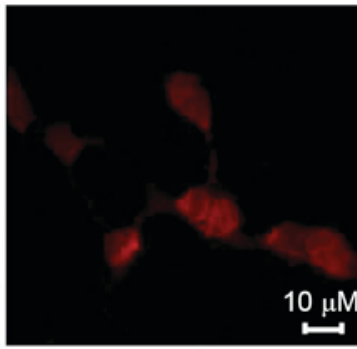

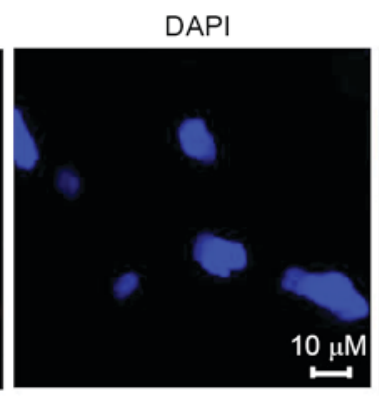

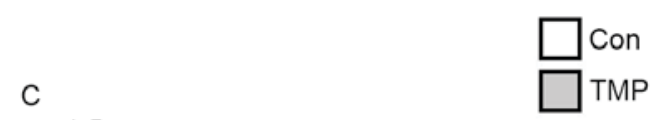

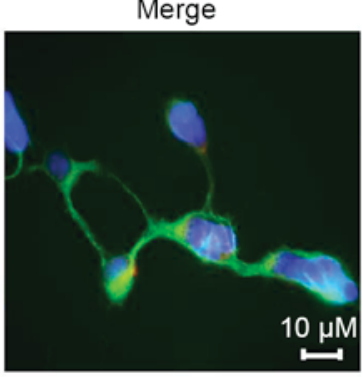

MP
B

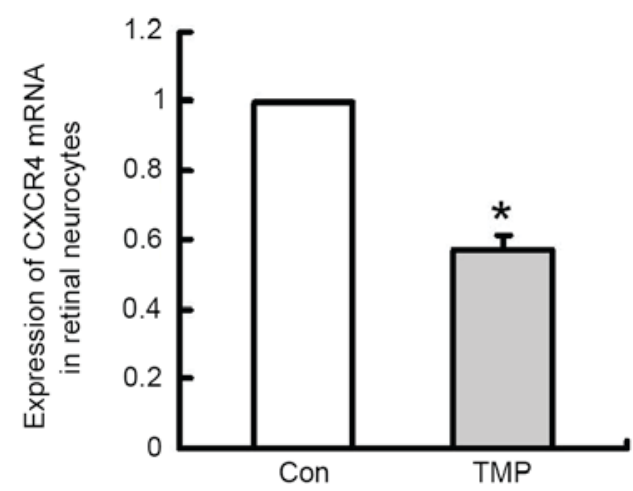

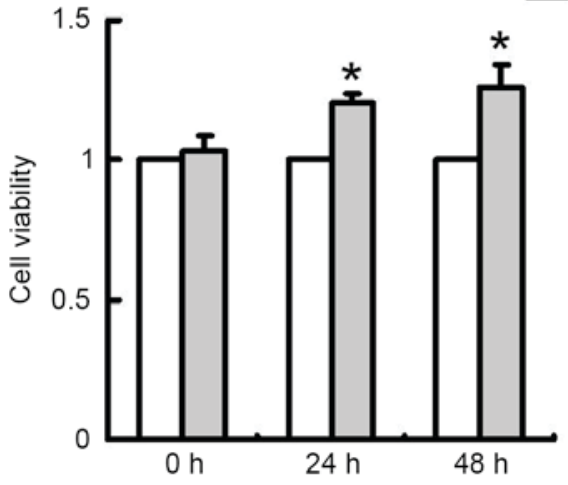

Figure 4. TMP reduces the expression of CXCR4 in primary rat retinal neurocytes and protects them from $\mathrm{H}_{2} \mathrm{O}_{2}$-induced damage. (A) Immunohistofluorescence results indicate that CXCR4 is present on primary rat retinal neurocytes. CXCR4 (red), MAP-2 (green) and DAPI-stained nuclei (blue) were visualized in primary rat retinal neurocytes. (B) Reverse transcription-polymerase chain reaction demonstrates that the expression CXCR4 in primary retinal neurocytes is reduced by treatment with $200 \mu \mathrm{M}$ TMP. (C) TMP promotes neuronal survival by protecting against $\mathrm{H}_{2} \mathrm{O}_{2}$-induced damage. $\mathrm{H}_{2} \mathrm{O}_{2}$ treatment with no TMP was used as the control. All results were confirmed in three independent experiments ( ${ }^{*} \mathrm{P}<0.05$ vs. Con). MAP-2, microtubule associated protein-2; CXCR4, C-X-C chemokine receptor type 4; Con, control; TMP, tetramethylpyrazine.

Notably, TMP significantly downregulated CXCR4 expression in high-density WERI-Rb1 cells, however the effect was not as potent in cells cultured at low density. Based on these evidences, we hypothesize that TMP possesses a strong anti-retinoblastoma effect when a tumor is actively proliferating, thus may be of therapeutic value to supplement chemotherapy to inhibit tumor growth and metastasis. Elucidation of the mechanism of the TMP-mediated downregulation of $C X C R 4$ in high-density cells requires further investigation.

CXCR4 is closely associated with the cell cycle $(22,23)$, and its downregulation results in reductions in the expression of certain cell cycle-associated proteins, including cyclin D1, which is a subtype of cyclin D that affects the G1/S phase control point in the cell cycle $(24,25)$. Accordingly, the cell cycle profile data in the current study demonstrated that TMP treatment resulted in arrest of WERI-Rb1 cells in the G1 phase when the cells were cultured to a high density. These cell cycle data are similar to the results of our previous study (18), revealing that TMP only affects the cell cycle of glioma C6 cells at $100 \%$ confluency. However, the different cell type the previous study produced differing results, with TMP inducing arrest in the S phase in C6 cells, and significantly reducing the $\mathrm{G} 1$ and $\mathrm{G} 2$ populations compared with control cells (18). Therefore, TMP may reduce CXCR4 expression, and subsequently arrest the cell cycle at the G1 phase, eventually inhibiting tumor cell proliferation in retinoblastoma. Additionally, in the current study, the cell cycle of WERI-Rb1 cells was not altered after TMP treatment for $24 \mathrm{~h}$ at a low cell density, with only a minor inhibitory effect on cell proliferation. These data suggest that the cell cycle inhibition may a factor that affect retinoblastoma cell proliferation.

Furthermore, Chuanxiong has been used in the clinical setting $>2,000$ years, and its bioactive extract, TMP, is also an effective medicine currently used in the treatment of neural diseases in China (10-13). Our previous study has demonstrated that CXCR4 is a target gene of TMP in neural protection (14). The results of the present study demonstrated that CXCR4 was expressed in retinal MAP-2-positive cells in vitro, and TMP significantly downregulated $C X C R 4$ expression in retinal neurocytes and increased cell viability. Therefore, TMP not only inhibits retinoblastoma cell growth, it also protects retinal neurocytes.

In conclusion, the findings of the present study suggest that the TMP-mediated CXCR4 pathway may be sensitive to cell density. TMP could be a potentially effective and safe therapeutic agent to supplement chemotherapy during retinoblastoma treatment. The current study will extend the application of TMP treatment in clinical therapy.

\section{Acknowledgements}

This study was supported by grants from the National Natural Science Foundation (project no. 81370987). 


\section{References}

1. Meel R, Radhakrishnan V and Bakhshi S: Current therapy and recent advances in the management of retinoblastoma. Indian $\mathrm{J}$ Med Paediatr Oncol 33: 80-88, 2012.

2. Zhang Y, Liu X,Zuo T, Liu Y and Zhang JH: Tetramethylpyrazine reverses multidrug resistance in breast cancer cells through regulating the expression and function of P-glycoprotein. Med Oncol 29: 534-538, 2012.

3. Wang XB, Wang SS, Zhang QF, Liu M, Li HL, Liu Y, Wang JN, Zheng F, Guo LY and Xiang JZ: Inhibition of tetramethylpyrazine on P-gp, MRP2, MRP3 and MRP5 in multidrug resistant human hepatocellular carcinoma cells. Oncol Rep 23: 211-215, 2010.

4. Yin J, Yu C, Yang Z, He JL, Chen WJ, Liu HZ, Li WM, Liu HT and Wang YX: Tetramethylpyrazine inhibits migration of SKOV3 human ovarian carcinoma cells and decreases the expression of interleukin-8 via the ERK1/2, p38 and AP-1 signaling pathways. Oncol Rep 26: 671-679, 2011.

5. Cao J, Miao Q, Miao S, Bi L, Zhang S, Yang Q, Zhou X,Zhang M, Xie Y, Zhang J and Wang S: Tetramethylpyrazine (TMP) exerts antitumor effects by inducing apoptosis and autophagy in hepatocellular carcinoma. Int Immunopharmacol 26: 212-220, 2015.

6. Wang $\mathrm{XJ}, \mathrm{Xu} \mathrm{YH}$, Yang GC, Chen $\mathrm{HX}$ and Zhang P: Tetramethylpyrazine inhibits the proliferation of acute lymphocytic leukemia cell lines via decrease in GSK-3 $\beta$. Oncol Rep 33 2368-2374, 2015

7. Jiang Y, Liu C, Chen W, Wang H, Wang C and Lin N: Tetramethylpyrazine enhances vascularization and prevents osteonecrosis in steroid-treated rats. Biomed Res Int 2015 $315850,2015$.

8. Zhang L, Deng M and Zhou S: Tetramethylpyrazine inhibits hypoxia-induced pulmonary vascular leakage in rats via the ROS-HIF-VEGF pathway. Pharmacology 87: 265-273, 2011.

9. Cai X, Chen Z, Pan X, Xia L, Chen P, Yang Y, Hu H, Zhang J, $\mathrm{Li} \mathrm{K}, \mathrm{Ge} \mathrm{J}$, et al: Inhibition of angiogenesis, fibrosis and thrombosis by tetramethylpyrazine: Mechanisms contributing to the SDF-1/CXCR4 axis. PLoS One 9: e88176, 2014.

10. You JM, Zhang ZG, Liu C and Ji YX: Ischemic stroke and the regulation of syndrome of traditional Chinese medicine compound efficacy TMP combined. Chin Archives Tradit Chin Med 28: 2666-2668, 2010.

11. Tang ZY, Wang SL and Lin Y: Progress in protective effects of tetramethylpyrazine on diabetes complications in nervous system and possible mechanisms. Chin J Pharmacol Toxicol 25: $114-118,2011$.

12. Chen Y and Liu M: Systemic evaluation of security of ligustrazine for treatment of cerebral infarction. Chin J Clin Rehab 8 1299-1301, 2004.
13. Yang XG and Jiang C: Ligustrazine as a salvage agent for patients with relapsed or refractory non-Hodgkin's lymphoma. Chin Med J (Engl) 123: 3206-3211, 2010.

14. Chen Z, Pan X, Georgakilas AG, Chen P, Hu H, Yang Y, Tian S, Xia L, Zhang J, Cai X, et al: Tetramethylpyrazine (TMP) protects cerebral neurocytes and inhibits glioma by down regulating chemokine receptor CXCR4 expression. Cancer Lett 336: 281-289, 2013.

15. Furusato B, Mohamed A, Uhlén M and Rhim JS: CXCR4 and cancer. Pathol Int 60: 497-505, 2010.

16. Wang $X$ and Chen $X$ : Study on the effects of tetramethylpyrazine on tumor cells: Survey and prospects. Zhongguo Zhong Yao Za Zhi 28: 295-298, 2003 (In Chinese).

17. Muller A, Homey B, Soto H, Ge N, Catron D, Buchanan ME, McClanahan T, Murphy E, Yuan W, Wagner SN, et al: Involvement of chemokine receptors in breast cancer metastasis. Nature 410: 50-56, 2001.

18. Yu K, Chen Z, Pan X, Yang Y, Tian S, Zhang J, Ge J, Ambati B and Zhuang J: Tetramethylpyrazine-mediated suppression of C6 gliomas involves inhibition of chemokine receptor CXCR4 expression. Oncol Rep 28: 955-960, 2012.

19. Livak KJ and Schmittgen TD: Analysis of relative gene expression data using real-time quantitative PCR and the 2(-Delta Delta C(T)) method. Methods 25: 402-408, 2001.

20. Schulte A, Günther HS, Phillips HS, Kemming D, Martens T, Kharbanda S, Soriano RH, Modrusan Z, Zapf S, Westphal M and Lamszus K: A distinct subset of glioma cell lines with stem cell-like properties reflects the transcriptional phenotype of glioblastomas and overexpresses CXCR4 as therapeutic target. Glia 59: 590-602, 2011.

21. Darash-Yahana M, Pikarsky E, Abramovitch R, Zeira E, Pal B, Karplus R, Beider K, Avniel S, Kasem S, Galun E and Peled A: Role of high expression levels of CXCR4 in tumor growth, vascularization, and metastasis. FASEB J 18: 1240-1242, 2004.

22. Mo W, Chen J, Patel A, Zhang L, Chau V, Li Y, Cho W, Lim K, $\mathrm{Xu} \mathrm{J}$, Lazar AJ, et al: CXCR4/CXCL12 mediate autocrine cell-cycle progression in NF1-associated malignant peripheral nerve sheath tumors. Cell 152: 1077-1090, 2013.

23. Yang P, Wang G, Huo H, Li Q, Zhao Y and Liu Y: SDF-1/CXCR4 signaling up-regulates survivin to regulate human sacral chondrosarcoma cell cycle and epithelial-mesenchymal transition via ERK and PI3K/AKT pathway. Med Oncol 32: 377, 2015.

24. Yu T, Wu Y, Huang Y, Yan C, Liu Y, Wang Z, Wang X, Wen Y, Wang $\mathrm{C}$ and Li L: RNAi targeting CXCR4 inhibits tumor growth through inducing cell cycle arrest and apoptosis. Mol Ther 20: 398-407, 2012.

25. Ji AJ, Liu SL, Ju WZ and Huang XE: Anti-proliferation effects and molecular mechanisms of action of tetramethypyrazine on human SGC-7901 gastric carcinoma cells. Asian Pac J Cancer Prev 15: 3581-3586, 2014. 